\title{
Pengaruh Critical Success Dalam Implementasi Enterprise Resource Planning (ERP) Terhadap Kinerja Perusahaan Studi Pada PT. Angkasa Pura II (Persero)
}

\author{
Rezi Eka Putra \\ Universitas Pamulang \\ dosen02025@unpam.ac.id
}

\begin{abstract}
This study aims to determine the effect of the critical success factor in the implementation of enterprise resource planning (ERP) and company performance study at PT Angkasa Pura II (Persero). Critical success factor was measured by using a variable business process reengineering (BPR), education and training (DIKLAT), and support suppliers (VENDOR) towards success ERP implementation (KIMP). The company's performance is measured by looking at the net benefit of implementing ERP systems for companies (NETB). The result of Lisrel 8.8 has an analysis that shown to business process reengineering $(\mathrm{BPR}=2.41)$, education and training (DIKLAT $=5.53$ ), support suppliers (VENDOR $=4.30$ ) has a positive influence on the successful implementation of ERP (KIMP), and the successful implementation of ERP (KIMP = 10.10) positively influences to net benefit of implementing ERP systems for companies (NETB).

Keyword: critical success factor, successful implementation of ERP, net benefit for the company ERP implementation
\end{abstract}

\begin{abstract}
Abstrak
Penelitian ini bertujuan untuk mengetahui pengaruh critical success factor dalam implementasi enterprise resource planning (ERP) terhadap kinerja perusahaan studi pada PT Angkasa Pura II (Persero). Critical success factor diukur dengan menggunakan variabel business process reengineering (BPR), pendidikan dan pelatihan (DIKLAT), dan dukungan pemasok (VENDOR) terhadap keberhasilan implementasi ERP (KIMP). Kinerja perusahaan diukur dengan melihat net benefit dari implementasi sistem ERP bagi perusahaan (NETB). Hasil analisis Lisrel 8.8 yang dilakukan menunjukkan bahwa business process reengineering ( $\mathrm{BPR}=2.41$ ), pendidikan dan pelatihan (DIKLAT=5.53), dukungan pemasok (VENDOR=4.30) mempunyai pengaruh positif terhadap keberhasilan implementasi ERP (KIMP), dan keberhasilan implementasi ERP (KIMP=10.10) mempunyai pengaruh positif terhadap net benefit dari implementasi sistem ERP bagi perusahaan (NETB).

Kata Kunci: faktor penentu keberhasilan, keberhasilan implementasi ERP, keuntungan implementasi ERP bagi perusahaan
\end{abstract}

Diterima: 7 Agustus 2108; Revisi: 2018; Disetujui: 2018 


\section{PENDAHULUAN}

Persaingan global telah melahirkan standar kompetisi baru. Pada kondisi ini setiap perusahaan yang ingin tetap survive dan growth harus dapat menciptakan dan mempertahankan competitive advantage yang dimilikinya dengan terus-menerus meningkatkan daya saing. Persaingan bisnis yang semakin tinggi menuntut perusahaan untuk terus meningkatkan kinerja berbagai elemen di dalam organisasi/perusahaan (Suhendi, 2010).

Peningkatan kinerja perusahaan salah satunya dengan penerapan teknologi informasi dalam aktivitas perusahaan yang dapat meningkatkan keunggulan dan daya saing. Dalam rangka mewujudkan kehandalan informasi, perusahaan dapat menerapkan suatu sistem informasi yang dapat mengintegrasikan semua aktivitas dan fungsi yang ada di dalam perusahaan (Kurniawati \& Permadi, 2011).

Keberhasilan suatu sistem informasi juga dipengaruhi oleh kualitas sistem, kualitas layanan, kualitas informasi, dan kepuasan pengguna, faktor-faktor tersebut juga memiliki pengaruh terhadap kinerja individu. Semakin bagus kualitas sistem, kualitas layanan, dan kualitas informasi maka semakin tinggi kepuasan pengguna. Semakin tinggi kepuasan pengguna maka kinerja individu akan semakin meningkat (Istianingsih \& Utami, 2009).

Menurut Tarigan (2013) Implementasi sistem informasi yang ada dalam organisasi bisnis dimulai dari yang paling sederhana sampai yang paling kompleks, yang berbasis enterprise. Implementasi sistem informasi yang berbasis enterprise ini seringkali disebut sebagai Enterprise Resource Planning (ERP). Sekarang ini tidak hanya perusahaan besar yang menggunakan ERP tetapi juga perusahaan yang berskala menengah telah mulai menerapkan sistem ERP karena jika implementasi ERP sukses maka manfaat yang dirasakan seperti perbaikan layanan pelanggan, jadwal produksi yang lebih baik dan pengurangan biaya produksi akan dirasakan oleh perusahaan. Kesuksesan dan kegagalan dalam mengimplementasikan sistem ERP dipengaruhi oleh banyak faktor atau lebih dikenal dengan istilah Critical Succes Factor (CSF) yaitu dukungan manajemen puncak, manajemen proyek ERP, Business Process Reengineering, pendidikan dan 
pelatihan dan dukungan pemasok, serta keberhasilan implementasi mempengaruhi Net-Benefit bagi perusahaan (Tjakrawala \& Lukita, 2011).

Sebagai salah satu BUMN yang sedang tumbuh PT Angkasa Pura II (Persero) mempunyai visi sebagai to be world class airport. Untuk mendukung tercapainya visi tersebut PT Angkasa Pura II (Persero) mengimplementasikan suatu sistem yang terintegrasi (ERP) dan komprehensif sehingga diharapkan dapat mempercepat pencapaian proses bisnis di lingkungan perusahaan. Isi dari visi tersebut tertuang dalam Rencana Jangka Panjang Perusahaan (RJPP) yang merupakan pedoman arah kebijakan dan strategi pengembangan perusahaan dalam kurun waktu tahun 2012 -2016.

Fokus pada penelitian ini berkaitan dengan pengaruh Business Process Reengineering terhadap keberhasilan implementasi ERP, pendidikan dan pelatihan terhadap keberhasilan implementasi ERP dan dukungan pemasok terhadap keberhasilan implementasi ERP di PT Angkasa Pura II (Persero). Kinerja perusahaan diukur dengan melihat net benefit dari implementasi sistem ERP bagi perusahaan (NETB).

Zouine \& Fenies (2014) mengungkapkan bahwa Rekayasa Proses Bisnis (Business Process Reengineering) sangat penting dalam implementasi sistem ERP. Untuk mendapatkan keuntungan dan cara terbaik dari sistem ERP, proses bisnis harus di design dan dirubah. Menurut Somers and Nelson (2004) model bisnis yang baru dan rekayasa ulang yang mendorong pilihan teknologi merupakan faktor yang memungkinkan memberikan keberhasilan ERP.

Tjakrawala \& Lukita (2011) mengungkapkan bahwa salah satu alasan pokok mengapa ERP dan sistem canggih lainnya gagal adalah organisasi tidak memperdulikan sejauh mana mereka harus berubah dan rekayasa ulang proses bisnis yang ada dalam rangka untuk mengakomodasi pembelian mereka. Sistem ERP dibangun atas dasar praktek-praktek terbaik yang diikuti dalam industri. Semua proses dalam perusahaan harus sesuai dengan model ERP.

Pendidikan dan pelatihan pengguna untuk menggunakan ERP penting karena ERP bukan sebuah sistem yang mudah digunakan, bahkan dengan 
kemampuan teknologi informasi yang baik. Untuk membuat pelatihan pengguna akhir berhasil, pelatihan harus dimulai sejak dini, sebaiknya jauh sebelum implementasi dimulai (Umble, et al, 2003).

Zhang, et al (2002) berargumen bahwa alasan utama untuk pendidikan dan pelatihan adalah untuk meningkatkan keahlian dan pengetahuan pengguna dalam perusahaan. Pendidikan dan pelatihan mengacu kepada proses menyediakan suatu pemahaman tentang logika dan keseluruhan konsep sistem ERP. Tjakrawala \& Lukita (2011) mengungkapkan bahwa alasan utama untuk pendidikan dan pelatihan adalah meningkatkan tingkat keahlian dan pengetahuan orang-orang dalam perusahaan.

Suatu ERP memerlukan investasi yang terus menerus dalam hal penambahan modal baru dan upgrade untuk menambahkan fungsionalitas, mencapai kecocokan yang lebih baik antara bisnis dengan sistem, dan menyadari nilai strategis mereka. Akibatnya, dukungan pemasok dalam bentuk bantuan teknis, pemeliharaan darurat, pembaruan, dan pelatihan pengguna khusus, merupakan faktor penting yang dikemas dengan perangkat lunak ERP pada tahap implementasi (Dezdar dan Ainin, 2010).

Tjakrawala \& Lukita (2011) mengungkapkan sangat penting bagi staff vendor untuk memiliki keterampilan interpersonal dan mampu bekerja dengan orang lain. Pemasok perangkat lunak harus dipilih dengan hati-hati karena mereka yang memegang bagian penting dalam membentuk hasil akhir dari pelaksanaan.

Ji dan Min (2005) mengungkapkan bahwa sukses ERP bisa dilihat dari aspek individual impact, organizational impact, information quality, dan system quality. Untuk beberapa perusahaan sangat sulit untuk mengukur keberhasilan implementasi ERP dengan menggunakan sebuah ukuran seperti manfaat keuangan. Delone and McLane (2003) mengungkapkan net benefit sebagai suatu ukuran untuk mengukur efek positif dari sistem informasi dan menunjukkan bahwa masing-masing subjek studi harus menentukan dimana manfaat ini akan terjadi atau siapa yang menerima manfaat.

Tjakrawala \& Lukita (2011) mengungkapkan bahwa untuk mengukur keberhasilan sistem ERP dibagi kedalam tiga kategori yaitu sistem quality, 
information quality dan service quality. Keberhasilan implementasi ERP mempunyai pengaruh positif terhadap net-benefit sistem ERP bagi perusahaan.

\section{METODE}

Skala pengukuran yang digunakan dalam penelitian ini adalah menggunakan skala Interval, dengan menggunakan metode skala Likert. Skala Likert merupakan metode yang mengukur sikap dengan menyatakan setuju atau ketidaksetujuannya terhadap subjek, objek, atau kejadian tertentu (Sekaran, 2015). Populasi dalam penelitian ini adalah karyawan (user) yang menggunakan aplikasi ERP di PT Angkasa Pura II (Persero). Metode pemilihan sampel digunakan purposive sampling dengan kriteria sebagai berikut: (1) Terbiasa menggunakan aplikasi ERP minimal 1 bulan; (2) Berpendidikan minimal S1 (Sarjana) karena diharapkan mampu memberikan kontribusi untuk analisis implementasi ERP; (3)Berada diwilayah jakarta karena pengguna terbesar aplikasi ERP PT Angkasa Pura II (Persero) berada di jakarta; (4)Besarnya sampel ditentukan berdasarkan jumlah responden yang mengembalikan kuesioner.

Data diolah dengan menggunakan Structural Equation Model (SEM). Pemilihan metode SEM sesuai dalam menganalisis data yang berasal dari kuesioner. Chin \& Todd (1995) juga menyatakan bahwa penggunaan Structural Equation Modeling (SEM) dengan programnya (LISREL, EQS, PLS), dapat meningkatkan teknik analisis dalam riset sistem informasi. Terdapat dua persamaan struktural yang digunakan dalam penelitian ini yaitu

$$
\begin{gathered}
\text { Persamaan struktural } 1 \\
\mathrm{KIMP}=\beta 0+\beta 1 * \mathrm{BPR}+\beta 2 * \text { DIKLAT }+\beta 3 * \text { VENDOR }+\mathrm{e} \\
\text { Persamaan struktural } 2 \\
\text { NETB }=\gamma 0+\gamma 1 * \text { KIMP }+\mathrm{e}
\end{gathered}
$$

Keterangan:

$\mathrm{BPR}=$ Business Process Reengineering

DIKLAT = Pendidikan dan Pelatihan

VENDOR = Dukungan Pemasok 




Teknik yang digunakan untuk uji validitas ini yaitu, teknik Confirmatory Factor Analysis (CFA) dengan program Lisrel 8.8 (Ghozali, 2014). Butir dinyatakan valid jika Standarized Loading Factors (SLF) $\geq 0,50$. Jadi apabila korelasi antara butir-butir dengan skor total kurang dari 0,50 maka butir dalam instrument tersebut dinyatakan tidak valid. Untuk uji reliabilitas ini digunakan dengan teknik construct reliability, dimana suatu instrument dapat dikatakan handal (reliable) bila nilai Construct reliability nya (CR) besar atau sama dengan $\geq 0,70$ (Ghozali, 2014). Dengan construct reliability $=(\text { jumlah standard loading factor })^{\wedge} 2 /(($ jumlah standard loading factor $\left.)^{\wedge} 2\right)+($ Standar error $)$ ). Selain itu Pada tahap ini akan dilakukan pengujian terhadap kesesuaian model melalui berbagai kriteria goodness of fit. Berikut beberapa indeks kesesuaian dan cut off value untuk menguji apakah sebuah model dapat diterima atau akan ditolak (Ghozali, 2014).

\section{HASIL DAN PEMBAHASAN}

Jumlah kuesioner yang disebarkan dibulan juni 2016 sebanyak 150 eksemplar dan oktober 2016 sebanyak 20 eksemplar sehingga totalnya 170 eksemplar. Dari jumlah tersebut, 24 kuesioner tidak kembali atau tidak mendapat respon. Sehingga kuesioner yang kembali sebanyak 146 kuesioner dan 1 kuesioner tidak dapat digunakan karena tidak lengkap. Karakteristik responden dalam penelitian ini disajikan dalam tabel 1.

Berdasarkan hipotesis H1, menyatakan bahwa Business Process Reengineering mempunyai pengaruh positif terhadap keberhasilan implementasi sistem ERP. Dapat dilihat dari path diagram pada lampiran, hasil pengujian model memperlihatkan bahwa $t$-value yaitu 2.41 dengan warna hitam yang berarti $t$-value $>1,96$. Sehingga menunjukkan bahwa Hipotesis $\underline{H 1}$ terbukti atau diterima.

Hasil penelitian ini tidak konsisten dengan penelitian terdahulu (Tjakrawala \& Lukita, 2011), dan Zhang, et al (2002), Dezdar and Ainin (2011). Dengan argumen bahwa dengan mengimplementasikan sistem ERP dapat 
mengintegrasikan sistem informasi manajemen lainnya dan memperoleh standarisasi proses bisnis yang ada di perusahaan. Memastikan tidak ada perubahan data antara setiap proses bisnis dan menjamin akurasi data. Dimensi tentang business process reengineering yaitu kesediaan perusahaan untuk rekayasa ulang, kesiapan perusahaan untuk perubahan, kemampuan perusahaan untuk rekayasa ulang dan komunikasi.

Tabel 1 Karakteristik Responden

\begin{tabular}{|c|c|c|c|}
\hline Karakteristik & Kategori & Jumlah & Persentase (\%) \\
\hline \multirow[t]{4}{*}{ Usia responden } & $20-27$ & 50 & 34,48 \\
\hline & $28-35$ & 84 & 57,93 \\
\hline & $>35$ & 11 & 7,59 \\
\hline & Total & 145 & 100 \\
\hline \multirow[t]{3}{*}{ Jenis kelamin } & Laki-laki & 89 & 61,38 \\
\hline & Perempuan & 56 & 38,62 \\
\hline & Total & 145 & 100 \\
\hline \multirow[t]{4}{*}{ Pendidikan } & Diploma & 16 & 11,03 \\
\hline & S1 & 114 & 78,62 \\
\hline & S2 & 15 & 10,34 \\
\hline & Total & 145 & 100 \\
\hline \multirow[t]{5}{*}{ Jabatan } & Staff & 113 & 77,93 \\
\hline & Senior Officer & 20 & 13,79 \\
\hline & Manajer & 8 & 5,52 \\
\hline & Vice President & 4 & 2,76 \\
\hline & Total & 145 & 100 \\
\hline \multirow[t]{4}{*}{ Masa Kerja } & 1-4 tahun & 69 & 47,59 \\
\hline & 5-10 tahun & 65 & 44,83 \\
\hline & $>10$ tahun & 11 & 7,59 \\
\hline & Total & 145 & 100 \\
\hline
\end{tabular}

\section{Sumber: Data diolah}

Berdasarkan hipotesis H2, menyatakan bahwa Pendidikan dan pelatihan berpengaruh positif terhadap keberhasilan implementasi sistem ERP. Dapat dilihat dari path diagram lampiran, hasil pengujian model memperlihatkan bahwa t-value 
yaitu 5.53 dengan warna hitam yang berarti $t$-value $>1,96$. Sehingga menunjukkan bahwa Hipotesis $\underline{\mathrm{H} 2 \text { terbukti atau diterima. }}$

Hasil penelitian ini konsisten dengan penelitian sebelumnya (Tjakrawala \& Lukita, 2011), tetapi konsisten dengan Rasmy, et al (2005), dengan argumen bahwa semua pengguna harus dididik dan dilatih dalam penggunaan sistem ERP. Pelatihan harus dimulai dengan pendidikan tim proyek dalam sistem, lini dan manajemen proyek, serta berakhir dengan pengguna sistem (user). Harus ada evaluasi dan pendampingan kepada pengguna sistem secara berkala agar pemahaman terhadap sistem ERP bisa lebih maksimal. Dengan pelatihan dan pendidikan membuat percaya diri pengguna sistem (user) dalam menggunakan sistem yang baru.

Tabel 2 Uji Hipotesis

\begin{tabular}{rclcrc}
\hline NO & HIPOTESIS & \multicolumn{1}{c}{ PATH } & T-VALUE & T-TABEL & HASIL \\
\hline 1 & H1 & BPR $\rightarrow$ KIMP & 2,41 & 1,96 & Diterima \\
2 & H2 & DIKLAT $\rightarrow$ KIMP & 5,53 & 1,96 & Diterima \\
3 & H3 & VENDOR $\rightarrow$ KIMP & 4,30 & 1,96 & Diterima \\
4 & H4 & KIMP $\rightarrow$ NETB & 10,10 & 1,96 & Diterima \\
\hline
\end{tabular}

Sumber : Data diolah

Berdasarkan hipotesis H2, menyatakan bahwa Pendidikan dan pelatihan berpengaruh positif terhadap keberhasilan implementasi sistem ERP. Dapat dilihat dari path diagram lampiran, hasil pengujian model memperlihatkan bahwa $t$-value yaitu 5.53 dengan warna hitam yang berarti $t$-value $>1,96$. Sehingga menunjukkan bahwa Hipotesis $\underline{\mathrm{H} 2 \text { terbukti atau diterima. }}$

Hasil penelitian ini konsisten dengan penelitian sebelumnya (Tjakrawala \& Lukita, 2011), tetapi konsisten dengan Rasmy, et al (2005), dengan argumen bahwa semua pengguna harus dididik dan dilatih dalam penggunaan sistem ERP. Pelatihan harus dimulai dengan pendidikan tim proyek dalam sistem, lini dan manajemen proyek, serta berakhir dengan pengguna sistem (user). Harus ada evaluasi dan pendampingan kepada pengguna sistem secara berkala agar pemahaman terhadap sistem ERP bisa lebih maksimal. Dengan pelatihan dan 
pendidikan membuat percaya diri pengguna sistem (user) dalam menggunakan sistem yang baru.

Berdasarkan hipotesis H3, menyatakan bahwa Dukungan pemasok mempunyai pengaruh positif terhadap keberhasilan implementasi sistem ERP. Dapat dilihat dari path diagram lampiran, hasil pengujian model memperlihatkan bahwa $t$-value yaitu 4.30 dengan warna hitam yang berarti $t$-value $>1,96$. Sehingga menunjukkan bahwa Hipotesis $\underline{\mathrm{H} 3 \text { terbukti atau diterima. }}$

Hasil penelitian ini tidak konsisten dengan penelitian sebelumnya (Tjakrawala \& Lukita, 2011), Rasmy, et al (2005). Dengan argumen bahwa dalam implementasi sistem ERP dukungan pemasok (vendor) selalu memberikan dukungan teknis yang memadai. Pemasok (vendor) mempunyai kredibilitas dan terpercaya dalam mengimplementasikan sistem ERP. Pemasok (vendor) dalam mengimplementasikan sistem ERP memiliki hubungan dan komunikasi yang baik dengan perusahaan/organisasi. Selain itu konsultan yang membantu memiliki pengalaman dan wawasan yang kompeten tentang sistem ERP. Konsultan memberikan pelatihan dan sharing knowledge yang berkualitas kepada perusahaan.

Berdasarkan hipotesis H4, menyatakan bahwa Keberhasilan implementasi ERP mempunyai pengaruh positif terhadap Net-Benefit sistem ERP bagi perusahaan. Dapat dilihat dari path diagram lampiran, hasil pengujian model memperlihatkan bahwa t-value yaitu 10.10 dengan warna hitam yang berarti $t$ value $>1,96$. Sehingga menunjukkan bahwa Hipotesis $\underline{\mathrm{H} 4 \text { terbukti atau diterima. }}$

Hasil penelitian ini konsisten dengan penelitian sebelumnya (Tjakrawala \& Lukita, 2011), dengan argumen bahwa Net Benefit mengukur efek positif dari suatu sistem informasi (Delone and Mclean, 2002) yang menunjukkan bahwa masingmasing subyek studi harus menentukan dimana manfaat ini akan terjadi atau siapa penerima manfaatnya. Individual dan organisasi yang secara khusus bertujuan untuk mencapai tujuan bisnis dan meningkatkan kemampuan operasional setelah implementasi sistem ERP. 


\section{SIMPULAN}

Berdasarkan hasil penelitian penulis dapat menyimpulkan bahwa Business process reengineering, pendidikan dan pelatihan, dan dukungan pemasok mempunyai pengaruh positif terhadap keberhasilan implementasi sistem ERP. Keberhasilan implementasi sistem ERP juga mempunyai pengaruh positif terhadap Net benefit sistem ERP bagi perusahaan.

Implementasi ERP membutuhkan komitmen dan konsisten dari semua pihak baik itu manajemen pucak, manajemen proyek serta penggunanya. Penolakan terhadap perubahan teknologi biasanya dikarenakan adanya kekhawatiran yang tidak beralasan terhadap keleluasaan dan wibawa, standar yang baru, tindakan pengendalian, kenaikan biaya dan belajar sesuatu yang baru. Proyek implementasi akan berhasil jika manajemen proyek dapat mengatur dan menyeimbangkan hal-hal seperti ruang lingkup proyek ERP, rencana implementasi, waktu, kualitas, biaya, sumber daya manusia, risiko, komunikasi dan pengadaan. Pendidikan dan pelatihan yang memadai karena ERP bukanlah sebuah sistem yang mudah digunakan (not user friendly) dan harus ada evaluasi secara berkala. Net benefit sistem ERP bagi perusahaan dapat dirasakan secara individual dan organisasi untuk mencapai tujuan bisnis dan meningkatkan kemampuan operasional setelah implementasi sistem ERP.

Berdasarkan hasil uji kecocokan model (Goodness of Fit) masih terdapat beberapa kriteria yang kurang baik. Hal ini mungkin dikarenakan jumlah sampel yang digunakan dalam penelitian ini masih perlu di tambah. Disarankan untuk penelitian selanjutnya menambah jumlah sampel yang digunakan agar hasil uji kecocokan model (Goodness of Fit) dalam Struktural Equation Model (SEM) dihasilkan model dengan tingkat kecocokan yang baik.

Critical success factor dalam keberhasilan implementasi ERP sangat komplek, sementara yang digunakan dalam penelitian ini masih terlalu sedikit untuk menguji keberhasilan implementasi sistem ERP. Disarankan kepada peneliti selanjutnya untuk menambahkan indikator-indikator lain yang menjadi kunci kesuksesan dalam keberhasilan implementasi ERP. Indikator tersebut misalnya dukungan manajemen puncak, manajemen proyek yang efektif, peranan keyuser, 
motivasi bisnis, motivasi teknologi, resiko, kualitas sistem, kualitas informasi, efektif design of process implementation, strong of technology ERP dan ERP data management sehingga menarik untuk diteliti pada penelitian selanjutnya.

\section{PUSTAKA ACUAN}

Abu-shanab, Emad, et al. 2015. Critical Success Factors for ERP Implementation : The Case of Jordan. International Arab Journal of Technology, Vol. 4 Nomor 1 , hal 1-7

Ajzen, Icek. 1991. The Theory of Planned Behavior. Organizational Behavior and Human Decision Processes. Hal 179-211

Ajzen, Icek., \& Fishbein, M. 1981. Understanding attitudes and predicting social behavior. Englewood Cliffs, NJ : Prentice-Hall

Aryani, Y. Anni. 2012. Pengaruh Implementasi Sistem Enterprise Resource Planning terhadap Kualitas Informasi Akuntansi. Universitas Negeri Surabaya

Chandra, Cisilia Tinny \& Augustine, Yvonne. 2015. Dampak Implementasi Enterprise Resource Planning (ERP) yang diukur dengan Metode Balanced Scorecard terhadap Kinerja Manajerial (Studi Kasus pada perusahaan yang menerapkan ERP Microsoft Dynamics Axapta di Indonesia. Jurnal Magister Akuntansi Trisaksi, Vol. 2 Nomor 1, 1 Februari 2015, Hal 1-24

Chin, Wynne. W, and Todd, Peter, A. 1995. On the Use, Usefulness, and Ease of Use A Structural Equation Modeling in MIS Research : A note of Caution. MIS Quarterly, 19 : 237-346

Davis, F. D. 1989. Perceived Usefulness, Perceived Ease of Use, and User Acceptance of Information Technology. MIS Quarterly, Society for Management Information Systems 13 (3). Hal 319-340

DeLone, W.H and E.R McLean. 2003. DeLone and McLean Model of information System Success:: A Ten-Year Update. Journal of Management Information System 19 (4). Hal 9-30

Fitriasary, Dewi dan Kwary, Deny Arnos. 2005. sistem informasi ERP. (Enterprise Resource Planning).http://www.intacsindo.com/ Jakarta 
ERP PT AP II, 2014. Buku Laporan Implementasi ERP Phase I PT Angkasa Pura II (Persero). Jakarta

Ganesh, L and Arpita Mehta. 2010. Critical Success Factors for successful Enterprise Resource Planning implementation at indian SMEs. International Journal of Business, Management dan Social Sciences (1). Hal 65-78.

Ghozali, Imam dan Fuad, 2014. Structural Equation Modeling Teori, Konsep dan Aplikasi dengan Program Lisrel 9.10. Semarang

Herlia, Yani. 2013. Pengaruh Implementasi Sistem Enterprise Resource Planning terhadap Kualitas Informasi Akuntansi (studi pada PT INTI Bandung). Universitas Negeri Surabaya

Hall, James A. 2002. Enterprise Resource Planning Information System Software Solution. www.google.com

Istianingsih \& Utami, Wiwik. 2009. Pengaruh Kepuasan Pengguna Sistem Informasi terhadap Kinerja Individu, Simposium Nasional Akuntansi 12, Palembang

Irfani, M.Hafiz. 2015. ERP (Enterprise Resource Planning dan aspek-aspek penting dalam penerapannya, Jurnal Eksplora Informatika, Vol. 4 Nomor 2, Hal 237

Kurnia, Indah, et al. 2012. Model Konseptual Keberhasilan ERP sebagai Pendekatan Multidimensi Motivasi Bisnis Dan Teknologi, Manfaat, Resiko serta Faktor Kunci Kesuksesan. Jurnal Sistem Informasi, Vol. 4 Nomor 3, hal 157-168

Kurniawati, Elisabeth Penti \& Permadi, F.X Rahardian Eka. 2011. Penerapan Enterprise Resource Planning System pada PT Garuda Indonesia (Persero). Universitas Kristen Satya Wacana

Mulia Hartono. 2008. 7 langkah mudah membangun sistem informasi ERP. www.intacsindo.com

Ozorhon, Beliz and Emrah Cinar. 2015. Critical Success Factors of Enterprise Resource Planning implementation in Construction : Case of Turkey. University of Manchester

Rasmy, et al. 2005. Enterprise Resource Planning (ERP) Implementation in the Egyptian Organizational Context. European and Mediterranean Conference on Information Systems. 
Sariningsih, Eka. 2013. Implementasi Enterprise Resource Planning System Pada Akuntansi Manajemen. Jurnal Riset Akuntansi dan Manajemen, Vol. 2 Nomor 1, Juni 2013 Hal 64-70

Sa'diyah, Melia Anisa \& Mudiantono. 2015. Analisis Kinerja Pemasaran melalui Keberhasilan Implementasi Sistem Enterprise Resource Planning (ERP) pada UMKM di Semarang. Universitas Diponegoro

Sekaran, Uma. 2015. Research Methods For Business. Fourth Edition, John Willey \& Sonc, Inc. Penerjemah Kwan Men Yon. Jakarta. Salemba Empat

Sigalotang, Widi Asnita, et al. 2014. Media Infusi Sistem Informasi atas Pengaruh Pemanfaatan Sistem Informasi terhadap Kinerja Pengguna Enterprise Resource Planning (ERP), Simposium Nasional Akuntansi 17, Mataram Lombok

Suhendi. 2010. Peran Enterprise Resource Planning (ERP) dalam meningkatkan kinerja perusahaan, http://suhendi.blogstudent.mb.ipb.ac.id/

Smith, Philp. 2008. ERP Software Solution. www.google.com

Susanto, Azhar. 2008. Sistem Informasi Enterprise Resource Planning. www.google.com

Setyoningsih, Dwianoegrahwati dan Almahdi, Indra. 2008. sistem informasi ERP. (Enterprise Resource Planning).http://www.intacsindo.com/ Jakarta

Tarigan, Josua. 2013. Enterprise Resource Planning (ERP) : Dampak dalam Pendidikan, Profesi Akuntan dan Auditor. Universitas Kristen Petra

Tarigan, Zeplin Jiwa Husada. 2009. Pengaruh Implementasi ERP terhadap Product Diffrentation dan Cost Leadership dalam Meningkatkan Kinerja Perusahaan (Studi Kasus Manufaktur Jawa Timur). Jurnal Manajemen Pemasaran, Vol. 4 Nomor 1, April 2009 hal 11-15

, et al. 2013. Analisa Implementasi Enterprise Resource Planning pada Perusahaan. Universitas Kristen Petra Surabaya

et al. 2011. Pengaruh Key User terhadap kinerja perusahaan pada implementasi teknologi Enterprise Resource Planning. Universitas Kristen Petra Surabaya 
Thompson, L and Cats-Baril, William L. 2008. Enterprise Resource Planning. www.google.com

Wikipedia. 2009. Perencanaan Sumber Daya Perusahaan 